OPEN ACCESS

Edited by:

Jose Antonio Lopez-Escamez, Granada University Hospital, Spain

Reviewed by: Eduardo Martin-Sanz, Hospital de Getafe, Spain Marcos Rossi-Izquierdo, Hospital Universitario Lucus Augusti, Spain

${ }^{*}$ Correspondence: Mira E. Ossen me.ossen@student. maastrichtuniversity.nl

Need for defining minimal outcome measures to pool data in meta-analysis.

Specialty section: This article was submitted to Neuro-otology, a section of the journal Frontiers in Neurology

Received: 27 April 2017 Accepted: 03 July 2017 Published: 24 July 2017

Citation:

Ossen ME, Stokroos R, Kingma $H$, van Tongeren J, Van Rompaey $V$, Temel $Y$ and van de Berg R (2017) Heterogeneity in Reported Outcome

Measures after Surgery in Superior

Canal Dehiscence Syndrome-A Systematic Literature Review.

Front. Neurol. 8:347.

doi: 10.3389/fneur.2017.00347

\section{Heterogeneity in Reported Outcome Measures after Surgery in Superior Canal Dehiscence Syndrome- A Systematic Literature Review}

\author{
Mira E. Ossen ${ }^{1 *}$, Robert Stokroos ${ }^{2}$, Herman Kingma ${ }^{2,3}$, Joost van Tongeren ${ }^{2}$, \\ Vincent Van Rompaey ${ }^{4,5}$, Yasin Teme ${ }^{6}$ and Raymond van de Berg ${ }^{2,3}$
}

${ }^{1}$ Faculty of Medicine, Maastricht University, Maastricht, Netherlands, ${ }^{2}$ Department of Otorhinolaryngology and Head \& Neck Surgery, Maastricht University Medical Center, Maastricht, Netherlands, ${ }^{3}$ Faculty of Physics, Tomsk State University, Tomsk Russian Federation, Tomsk, Russia, ${ }^{4}$ Faculty of Medicine and Health Sciences, University of Antwerp, Antwerp, Belgium, ${ }^{5}$ Department of Otorhinolaryngology and Head \& Neck Surgery, Antwerp University Hospital, Edegem, Belgium,

${ }^{6}$ Department of Neurosurgery, Maastricht University Medical Center, Maastricht, Netherlands

Background: Superior canal dehiscence syndrome (SCDS) can be treated surgically in patients with incapacitating symptoms. However, the ideal treatment has not been determined.

Objectives: This systematic literature review aims to assess available evidence on the comparative effectiveness and risks of different surgical treatments regarding: (1) symptom improvement; (2) objectively measurable auditory and vestibular function; (3) adverse effects, and (4) length of hospitalization.

Search method and data sources: A systematic database search according to PRISMA statement was conducted on Pubmed, Embase, and Cochrane library. In addition, reference lists were searched. No correspondence with the authors was established. The last search was conducted on June 9, 2017.

Study eligibility criteria: Retrospective and prospective cohort studies were held applicable under the condition that they investigated the association between a surgical treatment method and the relief of vestibular and/or auditory symptoms. Only studies including quantitative assessment of the pre- to postoperative success rate of a surgical treatment method were included. Case reports, reviews, meta-analysis, and studies not published in English, Dutch, or German were excluded.

Data collection and analysis: The first author searched literature and extracted data; the first and last analyzed the data.

Main results: Seventeen studies (354 participants, 367 dehiscences) met the eligibility criteria and were grouped according to surgical approach. Seven combinations of surgical approaches and methods for addressing the dehiscence were identified: plugging, resurfacing, or a combination of both through the middle fossa (middle fossa approach); plugging, resurfacing, or a combination of both through the mastoid (transmastoid approach); round window reinforcement through the ear canal (transcanal approach). 
Several studies showed high internal validity, but quality was often downgraded due to study design (1). Outcome measures and timing of postsurgical assessment varied among studies, making it unfeasible to pool data to perform a meta-analysis.

Conclusion: A standardized protocol including outcome measures and timeframes is needed to compare the effectiveness and safety SCDS treatments. It should include symptom severity assessments and changes in vestibular and auditory function before and after treatment.

Keywords: superior canal dehiscence syndrome, middle fossa, transmastoid, plugging, resurfacing

\section{INTRODUCTION}

\section{Rationale \\ Reason for Conducting This Research}

Superior canal dehiscence syndrome (SCDS) is a rare condition in which a hole in the superior semicircular canal causes sound and pressure waves to evoke vestibular and auditory symptoms. Symptoms can include sound- or pressure-induced vertigo (Tullio phenomenon), autophony, pulsatile tinnitus, bone conduction (BC) hyperacusis, conductive hearing loss, and "brain fog" (2-5). This broad variety of symptoms can make it difficult to distinguish SCDS from other neurological and otological pathologies. Migraine headaches for example can cause similar symptoms or present concurrently, but are treated differently (6). Patients with SCDS may be treated conservatively with education and observation. In more severe cases, however, surgical treatment is warranted when symptoms become incapacitating. Since the discovery of SCDS in 1998 by Lloyd Minor, who first referred to it as the "third window effect," a number of surgical techniques have been described $(3,5)$. Most techniques aim to relieve the patient's symptoms by closing the dehiscence and/or the plugging the semicircular canal. A recent alternative approach has suggested that occluding the round window through the ear canal may partially dampen the "third mobile window" effect (7). The dehiscence can be approached via middle cranial fossa of the skull ("middle fossa approach") or via the mastoid ("transmastoid approach"). Both middle fossa and transmastoid approaches allow resurfacing of the dehiscence as well as plugging of the canal and different materials have been used including fascia, bone chips, bone wax, fibrin glue and bone dust. Both approaches have shown high success rates in terms of symptom relief (5); however, each carries risks.

The ideal treatment should combine the safest approach with the most effective and durable closure technique. This ideal treatment has yet to be determined. A number of reviews have aimed to address this issue but have been limited to comparing highly variable outcome measures used to assess the different techniques (8-10). Despite an excellent internal setup, the risk of bias in most published studies is relatively high due to their retrospective study design and small sample size. Furthermore, different outcome measures have been used among the studies. Therefore, results can strictly speaking only be compared qualitatively and not be pooled. For instance, when comparing hearing outcomes across groups, studies report different frequency ranges (e.g., 0.25-4 vs.
$0.25-8 \mathrm{kHz}$ ). A high-frequency hearing loss may therefore be reported in one study, but not in another that only reports lower frequencies. Since systematic reviews provide clinical overviews and also advise clinicians on best practice methods, conclusions by authors should be drawn with care and be based on properly analyzed, pooled data. The PRISMA statement was chosen as a guideline as it focuses particularly on the evaluation of interventions. It is the preferred reporting guideline for systematic reviews and meta-analyses (11).

\section{Objective}

This systematic review aims to assess the evidence on the comparative efficacy of the different surgical treatments with respect to: (1) alleviating symptoms (BC hyperacusis, tinnitus, autophony, hearing, aural fullness, noise- and pressure-induced vertigo, and general disequilibrium); (2) change in objectively measurable auditory and vestibular function; (3) presence of adverse effects, and (4) length of hospitalization.

\section{METHODS}

\section{Protocol}

To structure this systematic review, the PRISMA statement for reporting systematic reviews was applied.

\section{Eligibility Criteria Inclusion Criteria}

Retrospective and prospective cohort studies were included if they analyzed the association between at least one surgical treatment method and its effect on symptom relief or auditory and vestibular function. To guarantee a minimum level of comparability, the success rates had to be assessed in a quantitative manner and had to be based on pre- and postoperative data.

In the context of this review, it was not feasible to translate literature, therefore only literature published in English, Dutch or German (i.e., languages spoken by the reviewing authors) was included. The search was constrained to studies on humans and to literature that was accessible through the library services of Maastricht University, the Academic Hospital Maastricht, or the Dutch Inter Library Loan Service. 


\section{Exclusion Criteria}

Studies were excluded if they did not analyze success rates in a quantitative manner, did not assess outcomes of one particular surgical treatment method, or did not use symptom relief as an outcome measure. Furthermore, the following types of literature were excluded: case reports, reviews, meta-analyses, and studies not published in English, Dutch, or German.

\section{Information Sources}

A systematic search was performed in the PubMed database, Embase database, and Cochrane library of clinical trials. Furthermore, the reference lists of selected articles were screened for additional literature. No unpublished literature was integrated into this review. The last search was conducted on June 9, 2017.

\section{Search}

We searched all three databases for abstracts, titles and key words containing suitable search terms. While searching PubMed we used the following terms:

((superior canal dehiscence syndrome) AND $\left(\left(\left(()\left(\left(()\left({ }^{\prime}\right.\right.\right.\right.\right.\right.$ Tinnitus”[Mesh] $) \quad O R$ tinnitus $\left.)\right) \quad O R$ (("Hyperacusis"[Mesh]) OR sound sensitivity)) OR autophony) OR phonophobia) OR (("Hearing Loss"[Mesh]) OR hearing impairment)) OR aural fullness) OR (("Pressure"[Mesh]) OR pressure)) OR (("Vertigo"[Mesh]) OR imbalance)) OR oscillopsia)) AND ((((()iddle fossa approach) OR transmastoid approach) OR endaural approach) OR resurfacing) $O R$ plugging) OR ((“Surgical Procedures, Operative”[Mesh]) OR surgical treatment))

Embase Database was searched using the following search terms:

\#1 "superior canal dehiscence syndrome"

\#2 "tinnitus" or "hyperacusis" or "sound sensitivity" or "autophony" or "phonophobia" or "hearing loss" or "hearing impairment" or "oral fullness" or "pressure" or "vertigo" or "imbalance" or "oscollopsia" or "tullio phenomenon"

\#3 "surgical treatment" or "surgical procedure" or "operation" or "middle fossa" or "middle fossa approach" or "transmastoid" or "transmastoid approach" or "endaural approach" or "resurfacing" or "plugging"

Cochrane Database of Clinical Trials was consequently searched with equivalent terms:

\#1 "superior canal dehiscence": ti,ab,kw or "superior canal dehiscence syndrome": ti,ab,kw or "MeSH descriptor: [Semicircular Canals] explode all trees" 0

\#2 "MeSH descriptor: [Tinnitus] explode all trees" or "MeSH descriptor: [Hyperacusis] explode all trees" or "MeSH descriptor: [Hearing Loss, Sensorineural] explode all trees" or "aural fullness": ti,ab,kw or "MeSH descriptor: [Pressure] explode all trees" or "vertigo": ti,ab,kw or "Tullio's phenomenon": ti,ab, kw or "autophony": ti,ab, kw 6317

\#3 "surgical treatment": ti,ab,kw or "MeSH descriptor: [General

Surgery] explode all trees" or "operation": ti, ab, kw 24360

\#4 "middle fossa": ti,ab,kw or "resurfacing": ti,ab,kw or "endaural approach": ti,ab, kw or "plugging": ti, ab, kw 25289

\#5 \#3 or "middle fossa": ti,ab,kw or "resurfacing": ti,ab,kw or

"endaural approach": ti,ab,kw or "plugging": ti,ab,kw 25289

\#6 \#1 and \#2 and \#50

\#5 \#2 and \#5 234

\section{Study Selection and Data Collection Process}

The first author screened titles and abstracts of the found articles to evaluate whether the content fit the inclusion and exclusion criteria. The first and last author analyzed the data in consensus.

\section{Data Items}

Data elements extracted from each study were as follows: study design, setting and duration of follow-up, country of origin, the number of participants, number of participants lost during follow-up, assessment tools and outcome measures.

\section{Risk of Bias in Individual Studies}

To evaluate the risk of bias for each study, specific methodological criteria were applied.

If relevant methodology was not addressed in the article, it was considered a risk for bias. The elements assessed for risk of bias that were included are presented in Table 1. A three-point scale was used to estimate the risk of bias for each component. The plus sign (+) indicates a low risk of bias. The sign $(+/-)$ is associated with elements that were rated with a moderate or unknown risk of bias. Studies were marked with a minus (-) if there was a high possibility of bias.

\section{Summary of Outcome Measures}

Different assessment tools were used (Table 2). Outcome measures could be divided into subjective and objective measures. Every measure that evaluated the subjective symptom improvement in patients was considered a primary outcome measure. Subjective outcomes were most-commonly extracted from non-standardized pre- or postoperative interviews and questionnaires. However, some studies used validated measures such as the dizziness handicap inventory (DHI), autophony index (AI), Hearing Handicap Inventory (HHI), or health utility value (HUV). The latter is an assessment tool to calculate the quality-adjusted life years, representing quality of life.

Measures that evaluated auditory or vestibular function were considered secondary outcome measurements in this review. The following objective outcome measures considered valid: standard pure-tone audiometry, word recognition/speech discrimination score, speech reception threshold (SRT), cervical vestibular-evoked myogenic potential (cVEMP), caloric testing, rotational chair testing, and electronystagmography. 


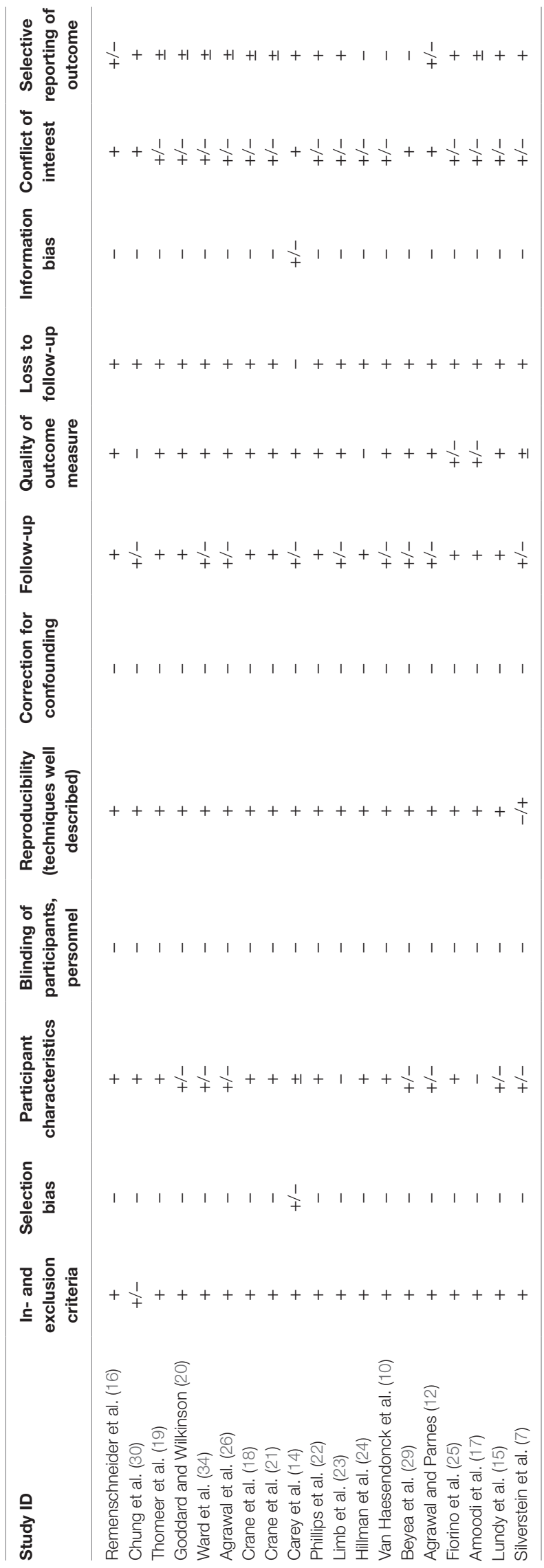

\section{RESULTS}

\section{Selected Studies}

The query returned 67 articles in PubMed, 20 articles in the Embase database, and 4 articles in the Cochrane Library. After removing duplicates 65 titles and abstracts were evaluated and 44 were excluded due to study design (case reports and reviews), outcome measures or because they were not available in the required languages. Reference lists of the remaining 21 articles were screened by title and abstract, resulting in an additional 7 articles for further evaluation. These 28 eligible studies were further analyzed for conformity with the remaining inclusion and exclusion criteria. After a full text screening, eight studies were excluded because they did not contain a quantitative measure of success. In addition, one article was excluded because it did not report the surgical approach. Nineteen studies were therefore included in this review.

\section{Study Characteristics Study Design}

The majority (18) of studies were retrospective chart reviews. The patient data collected for these chart reviews all contained pre- and postoperative information. However, the postoperative follow-up varied between 1 and 7 years. Only one prospective trial met the inclusion criteria.

\section{Country}

All 19 studies were conducted in countries with a mainly Caucasian population, either originating from the USA, Canada, France, Belgium, Italy, or Australia.

\section{Sample Size}

The number of cases in the retrospective studies varied between 3 (12) and 43 (13). The single prospective study consisted of 19 participants (14).

\section{Setting}

The majority of studies (18) were set in single, tertiary referral otology centers. There was only one multi-center retrospective chart review that evaluated patients from four institutions (7).

\section{Diagnosis}

In every study, the diagnosis of SCDS was based on vestibular and auditory symptoms and evidence of a dehiscence on CT imaging. In the majority of studies, VEMP thresholds were also used as a diagnostic tool but not uniformly and in many studies they were not mandatory for diagnosis. Clinically, patients mainly suffered from a combination of symptoms such as sound- and pressureinduced vertigo, chronic disequilibrium, autophony, aural fullness, pulsatile tinnitus, and hyperacusis. However, not all studies reported eligibility criteria for surgery and in some cases patients underwent surgery while suffering from one symptom alone (10). As mentioned above, migraine headaches are an important consideration in the differential diagnosis. However, it was not explicitly stated in any article whether migraine headaches were ruled out as the cause of the symptoms. 
TABLE 2 | Assessment tools for subjective and objective outcome measures.

\begin{tabular}{|c|c|c|c|c|c|c|c|c|c|c|}
\hline \multirow[t]{2}{*}{ Technique } & & \multirow[t]{2}{*}{ Study } & \multirow{2}{*}{$\begin{array}{l}\text { Assessment subjective } \\
\text { symptoms }\end{array}$} & \multicolumn{5}{|c|}{ Assessment objective measurements } & \multirow{2}{*}{$\begin{array}{c}\text { Time of } \\
\text { measurement } \\
\text { post surgery }\end{array}$} & \multirow{2}{*}{$\begin{array}{l}\text { Adverse } \\
\text { effects }\end{array}$} \\
\hline & & & & Audiometrics & $\begin{array}{l}\text { Vestibular-evoked } \\
\text { myogenic potentials } \\
\text { (VEMPs) }\end{array}$ & $\begin{array}{c}\text { Head } \\
\text { impulse test }\end{array}$ & Calorics & $\begin{array}{c}\text { Induced } \\
\text { nystagmus }\end{array}$ & & \\
\hline \multirow[t]{13}{*}{$\begin{array}{l}\text { Middle fossa } \\
\text { approach }\end{array}$} & $P$ & $\begin{array}{l}\text { Remenschneider et al. } \\
\text { (16) }(n=14)\end{array}$ & $\begin{array}{l}\text { Health utility value, } \\
\text { autophony index (AI), } \\
\text { dizziness handicap inventory } \\
\text { (DHI), and Hearing Handicap } \\
\text { Inventory }\end{array}$ & $x$ & $x$ & $x$ & $x$ & $x$ & 3 months & $x$ \\
\hline & $P+R$ & $\begin{array}{l}\text { Chung et al. }(30) \text {; } \\
21 \text { ears }(n=18)\end{array}$ & Anamnesis & $x$ & $x$ & $x$ & $x$ & $x$ & $x$ & $x$ \\
\hline & & $\begin{array}{l}\text { Thomeer et al. (19); } \\
16 \text { ears }(n=13)\end{array}$ & Anamnesis & $\begin{array}{l}\text { Tone: air conduction (AC), } \\
\text { bone conduction (BC), air } \\
\text { bone gap (ABG): } 0.25-1.0 \text { and } \\
0.5-4.0 \mathrm{kHz}\end{array}$ & $\begin{array}{l}\text { Cervical vestibular- } \\
\text { evoked myogenic } \\
\text { potentials (cVEMPs): } \\
\text { threshold, amplitude }\end{array}$ & $x$ & $x$ & $x$ & $\begin{array}{l}\text { D7 and } \\
1 \text { month }\end{array}$ & Reported \\
\hline & & & & $\begin{array}{l}\text { Speech: speech reception } \\
\text { threshold }\end{array}$ & & & & & & \\
\hline & & $\begin{array}{l}\text { Goddard and Wilkinson } \\
\text { (20); } 24 \text { ears }(n=23)\end{array}$ & Anamnesis & $\begin{array}{l}\text { Tone: AC, } \mathrm{BC}: 0.5-3 \mathrm{kHz} \\
\text { ABG: } 0.5-3 \mathrm{kHz}\end{array}$ & $x$ & $x$ & $x$ & $x$ & $x$ & Reported \\
\hline & & & & $\begin{array}{l}\text { Speech: Word Recognition } \\
\text { Score }\end{array}$ & & & & & & \\
\hline & & $\begin{array}{l}\text { Ward et al. (34); } \\
43 \text { ears }(n=40)\end{array}$ & $x$ & $\begin{array}{l}\text { Tone: AC: } 0.25-8 \mathrm{kHz}, \mathrm{BC}: \\
0.25-4 \mathrm{kHz}, \mathrm{ABG}: 0.25-2 \mathrm{kHz}\end{array}$ & $x$ & $x$ & $x$ & $x$ & $x$ & Reported \\
\hline & & $\begin{array}{l}\text { Agrawal et al. (26); } \\
42 \text { ears }\end{array}$ & $x$ & $x$ & $x$ & 1. Clinical & $x$ & $x$ & $x$ & $x$ \\
\hline & & & & & & $\begin{array}{l}\text { 2. Search } \\
\text { coil: } \\
\text { horizontal } \\
\text { canals }\end{array}$ & & & & \\
\hline & & $\begin{array}{l}\text { Crane et al. (18); } \\
19 \text { ears }\end{array}$ & $\mathrm{Al}, \mathrm{DHI}$ & $\begin{array}{l}\text { Tone: AC: } 0.25-8 \mathrm{kHz}, \mathrm{BC}: \\
0.25-4 \mathrm{kHz}, \mathrm{ABG}: 0.25-4 \mathrm{kHz}\end{array}$ & cVEMPs: thresholds & $x$ & $x$ & $x$ & $\begin{array}{l}3 \text { months: Al, } \\
\text { DHI }\end{array}$ & Reported \\
\hline & & $\begin{array}{l}\text { Crane et al. (21); } \\
19 \text { ears }\end{array}$ & $\mathrm{DHI}$ & $\begin{array}{l}\text { Tone: AC } 0.25-8 \mathrm{kHz}, \mathrm{BC} \text { : } \\
0.25-4 \mathrm{kHz}\end{array}$ & $\begin{array}{l}\text { cVEMPs: thresholds, } \\
\text { auditory stimuli }\end{array}$ & $x$ & $x$ & $x$ & 3 months: DHI & $x$ \\
\hline & & $\begin{array}{l}\text { Carey et al. (14); } \\
19 \text { ears }\end{array}$ & Anamnesis & $x$ & $x$ & $\begin{array}{l}\text { Search coil: } \\
\text { all canals }\end{array}$ & $x$ & $x$ & $1.5-7$ months & Reported \\
\hline & & $\begin{array}{l}\text { Phillips et al. (22); } \\
5 \text { ears }\end{array}$ & Anamnesis & $\begin{array}{l}\text { Tone: AC, BC (frequencies not } \\
\text { announced) }\end{array}$ & cVEMPs: thresholds & $x$ & $x$ & $x$ & 4 months & Reported \\
\hline
\end{tabular}


TABLE 2 | Continued

\begin{tabular}{|c|c|c|c|c|c|c|c|c|c|c|}
\hline \multirow[t]{2}{*}{ Technique } & & \multirow[t]{2}{*}{ Study } & \multirow{2}{*}{$\begin{array}{l}\text { Assessment subjective } \\
\text { symptoms }\end{array}$} & \multicolumn{5}{|c|}{ Assessment objective measurements } & \multirow{2}{*}{$\begin{array}{c}\text { Time of } \\
\text { measurement } \\
\text { post surgery }\end{array}$} & \multirow{2}{*}{$\begin{array}{l}\text { Adverse } \\
\text { effects }\end{array}$} \\
\hline & & & & Audiometrics & $\begin{array}{l}\text { Vestibular-evoked } \\
\text { myogenic potentials } \\
\text { (VEMPs) }\end{array}$ & $\begin{array}{c}\text { Head } \\
\text { impulse test }\end{array}$ & Calorics & $\begin{array}{l}\text { Induced } \\
\text { nystagmus }\end{array}$ & & \\
\hline & & Limb et al. (23); 29 ears & $x$ & $\begin{array}{l}\text { Speech: perception } \\
\text { Tone: AC: } 0.25-8 \mathrm{kHz}, \mathrm{BC}: \\
0.5-4 \mathrm{kHz}, \mathrm{ABG}: 0.25-8 \mathrm{kHz}\end{array}$ & $x$ & $x$ & $x$ & $x$ & $x$ & $x$ \\
\hline & $\mathrm{R}$ & $\begin{array}{l}\text { Hillman et al. (24); } \\
16 \text { ears }(n=13)\end{array}$ & Anamnesis & $\begin{array}{l}\text { Speech: SDS } \\
\text { Tone: AC, BC: } 0.5-3 \mathrm{kHz}, \mathrm{ABG} \\
\text { (frequencies not announced) } \\
\text { Speech: SDS }\end{array}$ & $x$ & $x$ & $x$ & $x$ & $>3$ months & $x$ \\
\hline \multirow[t]{6}{*}{$\begin{array}{l}\text { Transmastoid } \\
\text { approach }\end{array}$} & $\mathrm{P}$ & $\begin{array}{l}\text { Van Haesendonck } \\
\text { et al. (10); } 12 \text { ears }\end{array}$ & Anamnesis & $\begin{array}{l}\text { Tone: } \mathrm{AC}, \mathrm{BC}: 0.5-4 \mathrm{kHz}, \mathrm{ABG} \\
\text { (frequencies not announced) }\end{array}$ & $x$ & $x$ & $x$ & $x$ & $x$ & Reported \\
\hline & & $\begin{array}{l}\text { Beyea et al. (29); } \\
16 \text { ears }\end{array}$ & Anamnesis & $x$ & $x$ & $x$ & $x$ & $x$ & $x$ & Reported \\
\hline & & $\begin{array}{l}\text { Agrawal and Parnes } \\
\text { (12); } 3 \text { ears }\end{array}$ & Anamnesis & $\begin{array}{l}\text { Tone: AC, BC, ABG } \\
\text { (frequencies not announced) }\end{array}$ & $x$ & $x$ & $x$ & $x$ & $x$ & Reported \\
\hline & $P+R$ & $\begin{array}{l}\text { Fiorino et al. (25); } \\
6 \text { ears }\end{array}$ & Anamnesis & $\begin{array}{l}\text { Tone: AC, BC (frequencies not } \\
\text { announced) }\end{array}$ & VEMPs: thresholds & $x$ & $\begin{array}{l}\text { Procedure } \\
\text { not } \\
\text { described }\end{array}$ & $\begin{array}{l}\text { Sound and } \\
\text { pressure } \\
\text { induced, not } \\
\text { described. }\end{array}$ & $1.5-2$ months & Reported \\
\hline & $\mathrm{R}$ & $\begin{array}{l}\text { Amoodi et al. (17); } \\
4 \text { ears }\end{array}$ & Anamnesis & Tone: AC, BC: $0.25-8 \mathrm{kHz}$ & $x$ & $x$ & $x$ & $\begin{array}{l}\text { Sound and } \\
\text { pressure } \\
\text { induced, } \\
\text { procedure not } \\
\text { described. }\end{array}$ & $\begin{array}{l}\text { Not reported, } \\
\text { follow-up } \\
\text { varied between } \\
1.5 \text { and } 4 \text { years }\end{array}$ & Reported \\
\hline & & $\begin{array}{l}\text { Lundy et al. (15); } \\
37 \text { ears }\end{array}$ & $\begin{array}{l}\text { Scale from "worsening" to } \\
\text { "much better" }\end{array}$ & $x$ & $x$ & $x$ & $x$ & x & $>3$ months & $x$ \\
\hline $\begin{array}{l}\text { Transcanal } \\
\text { approach }\end{array}$ & RW & $\begin{array}{l}\text { Silverstein et al. (7); } \\
22 \text { ears }\end{array}$ & $\begin{array}{l}\text { Superior canal dehiscence } \\
\text { syndrome questionnaire } \\
\text { (7-point Likert type scale) }\end{array}$ & $x$ & $x$ & $x$ & $x$ & $x$ & $x$ & $x$ \\
\hline
\end{tabular}




\section{Approach and Closing Technique}

As mentioned above there were two primary surgical approaches (middle cranial fossa and transmastoid) and three different reparative techniques (plugging or resurfacing the superior semicircular canal alone and resurfacing with canal plugging). An alternative was transcanal reinforcement of the round window. Twelve studies examined the success rates of the middle cranial fossa approach. In 1 of the 12 studies, the superior semicircular canal was plugged, in 10 studies, the canal was plugged and resurfaced, and 1 study described the middle cranial fossa approach with resurfacing of the canal. The success rates for the transmastoid approach were assessed in six studies. Of the six studies, three involved plugging, one involved a combination of plugging and resurfacing, and two involved resurfacing alone [i.e., "cartilage cap occlusion" (15)]. Reinforcement of the round window through the ear canal was assessed in one study. It should be mentioned that one of the studies that mainly assessed plugging via the middle fossa also contained two patients who underwent transmastoid plugging (16). These cases could not be included in the analyses of this review since pre- and postoperative data were not reported in detail.

\section{Follow-up}

The follow-up of the retrospective studies, meaning the time until the last recorded data, varied from 1 month (13) to 4 years (17). A total of six studies, including the previously mentioned prospective study, did not report the duration of follow-up.

\section{Loss to Follow-up}

No loss to follow-up was reported in any retrospective study. In the prospective study, a loss to follow-up of 13 patients was reported resulting in a final population of 19 patients (14).

\section{Source of Data}

Retrospective studies collected and evaluated existing pre-and postoperative data from medical records. The one prospective study compared the existing preoperative data with new postoperative clinical records and auditory and vestibular measurements.

\section{Risk of Bias within Studies} Inclusion and Exclusion Criteria

All studies listed the inclusion and exclusion criteria.

\section{Selection Bias}

All retrospective studies were prone to selection bias and were therefore all graded with a ( -$)$. The prospective study was graded with a (+/-) due to an unclear risk of bias due to a lack of information on the patient selection process.

\section{Participant Characteristics}

With the exception of two studies, the patients' symptoms were clearly described. However, other patient demographics like age, sex, comorbidities, or otological history were often not described.

\section{Blinding}

Since blinding is not applicable to retrospective studies, 18 of the articles were graded with a minus (-). In the prospective study, the blinding of patients or surgeons was not required since there was no alternative treatment and therefore no control group.

\section{Reproducibility}

The surgical technique was well described in all 19 studies. However, in one study, surgeons used different techniques and materials, limiting reproducibility (7).

\section{Correction for Confounding}

Correction for confounding was not performed in any study.

\section{Follow-up}

The follow-up time differed greatly among studies. However, all studies had similar definitions for short-term and intermediateterm postoperative stages. This made it possible to compare early vs. late stage outcomes across the different studies.

Judgment on the length of follow-up depended upon the research question of each study. If a study aimed to investigate the short-term outcomes of the operation, several days could be considered a sufficient follow-up time. In comparison, a study that explored long-term outcomes required a follow-up of at least 12 months.

Out of the 19 studies, 10 presented a follow-up period of more than 3 months and were graded with a $(+)$. We considered a follow-up of more than 3 months as sufficient since the immediate postoperative side effect should, by that time, be resolved. The remaining nine studies presented a follow-up time that was reasonably aligned with their research question (e.g., short-term follow-up when focusing on immediate effects) and were therefore graded with a $(+/-)$.

\section{Quality of Outcome Measure}

The overall quality of outcome measures was moderate to low for the primary outcome measures that assessed subjective symptom improvement. They were mainly assessed through anamnesis and not standardized questionnaires that, for example, described "improvement," "worsening," or "no change in symptoms" (15). Standardized rating scales were: a questionnaire to measure an AI (18), the DHI, the HHI, the HUV, and a non-validated 7-point Likert type scale to assess the severity of each SCDS symptom (7).

The overall quality of outcome measure for the secondary objective outcome measurements was high. Theses included the following: audiometry $(10,12,13,15,17-25)$, vestibularevoked myogenic potentials (VEMPs) $(18,19,21,22,25)$, head impulse test (HIT) $(14,26)$, video head impulse test (vHIT) (26), caloric tests (25), and presence of induced nystagmus $(17,25)$. Audiometry comprised the air conduction (AC) pure-tone average (PTA), the BC PTA, the air bone gap (ABG) closure, and in some cases the SRT or the Word Recognition Score (WRS). A number of studies reported that values were calculated according to American Academy of Otolaryngology-Head and Neck Surgery Foundation (AAO-HNS) reporting guidelines (27). However, in the other cases, the precise assessment of outcome measures was not described. An additional outcome measure was the length of hospital stay in days and the presence of adverse effects. 


\section{Loss to Follow-up}

All 18 retrospective reports were graded with a $(+)$. The prospective study was considered to have a high risk of bias and was graded with a (-).

\section{Information Bias}

In a retrospective context, it was not possible to determine whether the information being used for the study was faulty or inaccurate. The risk for information bias was therefore considered high in all retrospective studies. All 18 retrospective chart reviews were therefore graded with a (-). Regarding the one prospective study, the risk for information bias was unclear and was graded with a (+/-).

\section{Conflict of Interest}

No conflicts of interest were reported, and there was no reason to suspect such in any of the studies. All studies were marked with a (+).

\section{Selective Reporting of Outcome}

Three articles were inconsistent with the reported numbers and results. They were therefore considered to have a high risk for bias and were therefore graded with a (-).

\section{Results of Individual Studies per Outcome Measure}

To increase comparability, the level of evidence and level of recommendation was added to each conclusion that follows a result analysis (28).

\section{Primary Outcomes-Subjective Improvement (Table 3) \\ BC Hyperacusis}

Bone conduction hyperacusis was not addressed in the studies that analyzed the effect of resurfacing, or a combination of resurfacing and plugging via the middle fossa. However, it was addressed in two studies that investigated transmastoid plugging. Symptoms resolved in seven of the nine affected patients (78\%) $(10,29)$. Improvement and resolution of hyperacusis were also not assessed following round window reinforcement.

Conclusion: Taking these results into account, no comparison could be made among the different approaches; however, BC hyperacusis was often resolved by transmastoid plugging. Grade of evidence: IV; grade of recommendation: D.

\section{Pulsatile and Non-Pulsatile Tinnitus}

Pulsatile tinnitus was assessed in six studies of which two studies also reported cases of non-pulsatile tinnitus. No evidence was available regarding plugging via the middle fossa. In one study plugging plus resurfacing via the middle fossa led to a resolution of pulsatile tinnitus in $10 / 12(p=0.0059)$ cases and led to the new development of pulsatile tinnitus in one case (30). In another study, it led to a resolution of pulsatile tinnitus in 12/12 cases $(100 \%)$ (19). In the same study, one patient experienced non-pulsatile tinnitus before surgery, but it was not reported whether symptoms resolved postoperatively. Resurfacing via the same approach led to a resolution in $2 / 3$ cases (67\%) (24). Transmastoid plugging resulted in the resolution of $16 / 19$ affected patients $(84 \%)(10,29)$. Following round window reinforcement using the transcanal approach, the score for tinnitus dropped from 4.6 to 2.2 on the SCDS 7-point Likert scale, where a score of 1 was not bothersome at all and a score of 7 was extremely bothersome $(n=22)(7)$.

Conclusion: Plugging, resurfacing and a combination of both via the middle fossa led to a resolution of symptoms in the majority of cases. This was similar for transmastoid approach plugging. Overall, tinnitus reduced following the transcanal approach to reinforcement of the round window. The middle fossa and transmastoid approach could not be compared with the transcanal approach, because different outcome measures were used. Overall, no validated questionnaires to assess tinnitus were used. Grade of evidence: IV; grade of recommendation: D.

\section{Autophony}

Plugging via the middle fossa showed a significant decrease in AI from 32.7 (SD 28.0) to 4.8 (SD 8.3, $p<0.001$ ) (16). Plugging plus resurfacing via the middle fossa showed reduction of autophony in four studies, with a resolution of symptoms in 32/40 patients $(19,20,30)$ and a significant drop in mean AI Score in $18 / 19$ patients from $42 \pm 27(0-86)$ to $9 \pm 22$ with a mean change of 33 points $(p<0.01)(18)$. However, one study reported improvement, but no resolution of autophony symptoms in 5/5 patients (22). No evidence was available on resurfacing alone via the middle fossa. Transmastoid plugging led to a resolution in $12 / 13$ patients (10, 12). No evidence was available regarding transmastoid resurfacing. Round window reinforcement led to a significant drop in autophony score from 4.6 to 2.2 on the SCDS 7-point Likert scale (7).

Conclusion: Plugging or plugging and resurfacing the dehiscence using the middle fossa or transmastoid approach as well as round window reinforcement led to significant improvements of autophony symptoms. Comparison of the different techniques was not possible due to different outcome measures. No evidence was available on the effect of resurfacing alone. Grade of evidence: IV; grade of recommendation: $\mathrm{D}$.

\section{Subjective Hearing Status}

Subjective change in hearing after surgery was addressed in four studies. One study addressed the effect of plugging via the middle fossa and indicated a reduction in HHI from 41.8 (SD 27.9) to 26.7 (SD 30.2, $p=0.140$ ) (16). Plugging plus resurfacing was also assessed in one study and led to an improvement in hearing in $6 / 10$ cases $(p=0.0858)$ (30). No evidence was available regarding the effects of resurfacing via the middle fossa. One study addressed the effect of transmastoid plugging and showed improvement in $2 / 16$ patients and a preservation of hearing in $14 / 16$ patients (29). No evidence was available on the effects of transmastoid resurfacing or a combination of plugging and resurfacing. Reinforcement of the round window also caused no significant change in the SCDS score for hearing on the 7-point Likert scale (7). 
TABLE 3 | Subjective improvement in affected ears.

\begin{tabular}{|c|c|c|c|c|c|c|c|c|c|c|c|c|}
\hline & & \multirow[t]{2}{*}{ Study } & \multicolumn{10}{|c|}{ Improvement of symptoms in affected ears } \\
\hline & & & HA & $\mathbf{T}$ & AP & $\mathbf{H}$ & AF & NIV & PIV & GD & Headache & $\begin{array}{l}\text { Quality of } \\
\text { life }\end{array}$ \\
\hline \multirow[t]{7}{*}{ Middle fossa } & $P$ & $\begin{array}{l}\text { Remenschneider et al. (16) } \\
(n=14)\end{array}$ & $x$ & $x$ & $\begin{array}{l}\text { Mean autophony } \\
\text { index (Al) }(n=14) \text { : } \\
\text { Pre: } 32.7(28.0) \\
\text { Post: } 4.8(8.3) \\
p<0.001\end{array}$ & $\begin{array}{l}\text { Mean } \\
\text { Hearing } \\
\text { Handicap } \\
\text { Inventory } \\
(n=14) \text { : } \\
\text { Pre: } 41.8 \\
(27.9) \\
\text { Post: } 26.7 \\
(30.2) \\
p=0.140\end{array}$ & $x$ & $x$ & $x$ & $\begin{array}{l}\text { Mean dizziness handicap } \\
\text { inventory }(D H I)(n=14) \text { : } \\
\text { Pre: } 48.7(23.4) \\
\text { Post: } 38.2(30.7) \\
p=0.200\end{array}$ & $x$ & $\begin{array}{l}\text { Mean } \\
\text { health } \\
\text { utility } \\
\text { value (SD) } \\
\text { Pre: } 0.65 \\
(0.12) \\
\text { Post: } 0.79 \\
(0.12) \\
p<0.001\end{array}$ \\
\hline & $P+R$ & $\begin{array}{l}\text { Chung et al. (30); } 21 \text { ears } \\
(n=18)\end{array}$ & $x$ & $\begin{array}{l}\text { Pre: } 12 / 18 \\
\text { Post: } 3 / 18 \\
\text { Developed: } 1 / 3 \\
p=0.0059\end{array}$ & $\begin{array}{l}\text { Pre: } 16 / 18 \\
\text { Post: } 5 / 18 \\
p=0.0005\end{array}$ & $\begin{array}{l}\text { Pre: } 10 / 18 \\
\text { Post: } 4 / 10 \\
p=0.0858\end{array}$ & $\begin{array}{l}\text { Pre: } 7 / 18 \\
\text { Post: } 3 / 18 \\
\text { Developed: } \\
2 / 3 \\
p=0.2642\end{array}$ & $\begin{array}{l}\text { Pre: } 13 / 18 \\
\text { Post: } 6 / 18 \\
\text { Developed: } \\
1 / 6 \\
p=0.0437\end{array}$ & $\begin{array}{l}\text { Pre: } 13 / 18 \\
\text { Post: } 6 / 18 \\
\text { Developed: } \\
1 / 6 \\
p=0.0437\end{array}$ & $\begin{array}{l}\text { Pre: } 11 / 18 \\
\text { Post: } 5 / 18 \\
\text { Developed: } 2 / 5 \\
p=0.0922\end{array}$ & $\begin{array}{l}\text { Pre: } 5 / 18 \\
\text { Post: } 4 / 18 \\
\text { Developed: } \\
1 / 4 \\
p=1.0000\end{array}$ & $x$ \\
\hline & & $\begin{array}{l}\text { Thomeer et al. (19); } 16 \text { ears } \\
(n=13)\end{array}$ & $x$ & $\begin{array}{l}\text { Resolved: } \\
\text { Pulsatile: 12/12 } \\
\text { Non-pulsatile: } \\
\text { O/1 }\end{array}$ & Resolved: $9 / 9$ & $x$ & $\begin{array}{l}\text { Resolved: } \\
6 / 6\end{array}$ & $\begin{array}{l}\text { Resolved: } \\
14 / 16\end{array}$ & $\begin{array}{l}\text { Resolved: } \\
\text { 10/10 }\end{array}$ & Resolved: 14/16 & $x$ & $x$ \\
\hline & & $\begin{array}{l}\text { Goddard and Wilkinson (20); } \\
24 \text { ears }(n=23)\end{array}$ & $x$ & $x$ & Resolved: 12/15 & $x$ & $\begin{array}{l}\text { Resolved: } \\
\text { 16/20 }\end{array}$ & $\begin{array}{l}\text { Resolved: } \\
8 / 8\end{array}$ & $\begin{array}{l}\text { Resolved: } \\
8 / 11\end{array}$ & Resolved: 16/24 & $x$ & $x$ \\
\hline & & $\begin{array}{l}\text { Ward et al. (34); } 43 \text { ears } \\
(n=40)\end{array}$ & $x$ & $x$ & $x$ & $x$ & $x$ & $x$ & $x$ & $x$ & $x$ & $x$ \\
\hline & & Agrawal et al. (26); 42 ears & $x$ & $x$ & $x$ & $x$ & $x$ & $x$ & $x$ & $x$ & $x$ & $x$ \\
\hline & & Crane et al. (18); 19 ears & & & $\begin{array}{l}\text { Mean Al }(n=18) \text { : } \\
\text { Pre: } 42 \pm 27 \text { (range } \\
\text { 0-86) } \\
\text { Post: } 9 \pm 22 \text { (range } \\
\text { 0-82) } \\
\text { Mean change: } 33 \\
(p<0.01 \text { ) }\end{array}$ & & & & & $\begin{array}{l}\text { Mean } D H I(n=18): \\
\text { Pre: } 48.22 \\
\text { Post: } 27.77\end{array}$ & $x$ & $x$ \\
\hline
\end{tabular}


TABLE 3 | Continued

\begin{tabular}{|c|c|c|c|c|c|c|c|c|c|c|c|c|}
\hline & & Study & & & & Improve & $t$ of $s$ & toms in aff & ted ears & & & \\
\hline & & & HA & $\mathbf{T}$ & AP & $\mathbf{H}$ & AF & NIV & PIV & GD & Headache & $\begin{array}{c}\text { Quality of } \\
\text { life }\end{array}$ \\
\hline & & Crane et al. (21); 19 ears & $x$ & $x$ & $x$ & $x$ & $x$ & $x$ & $x$ & $\begin{array}{l}\text { Mean DHI }(n=19) \text { : } \\
\text { Pre: } 44 \pm 24 \\
\text { Post: } 18 \pm 15 \\
p<0.01 \\
\text { Mean } \downarrow: 26 \pm 25 \\
p<0.01 \\
\text { Decreased: } 17 / 19 \\
\text { Increased: } 2 / 19\end{array}$ & $x$ & $x$ \\
\hline & & Carey et al. (14); 19 ears & $x$ & $x$ & $x$ & $x$ & $x$ & $\begin{array}{l}\text { Resolved: } \\
19 / 19\end{array}$ & $\begin{array}{l}\text { Resolved: } \\
19 / 19\end{array}$ & $x$ & $x$ & $x$ \\
\hline & & Phillips et al. (22); 5 ears & & & Improved: 5/5 & & & & & $\begin{array}{l}\text { Transient increase: } 4 / 5 \\
\text { Improved: } 5 / 5\end{array}$ & $x$ & $x$ \\
\hline & & Limb et al. (23); 29 ears & $x$ & $x$ & $x$ & $x$ & $x$ & $x$ & $x$ & $x$ & $x$ & $x$ \\
\hline & $\mathrm{R}$ & $\begin{array}{l}\text { Hillman et al. (24); } 16 \text { ears } \\
(n=13)\end{array}$ & $x$ & $\begin{array}{l}\text { Resolved: } \\
\text { Pulsatile: 2/3 } \\
\text { Non-pulsatile: - }\end{array}$ & $x$ & $x$ & $x$ & $x$ & $\begin{array}{l}\text { Resolved: } \\
12 / 12\end{array}$ & Resolved: 12/13 & $x$ & $x$ \\
\hline Transmastoid & $\mathrm{P}$ & $\begin{array}{l}\text { Van Haesendonck et al. (10); } \\
12 \text { ears }\end{array}$ & $\begin{array}{l}\text { Resolved: } \\
6 / 8\end{array}$ & $\begin{array}{l}\text { Resolved: } \\
\text { Pulsatile: 6/9 } \\
\text { Non-pulsatile: - }\end{array}$ & Resolved: 11/12 & $x$ & $x$ & $\begin{array}{l}\text { Resolved: } \\
4 / 5\end{array}$ & $\begin{array}{l}\text { Resolved: } \\
2 / 5 \\
\text { Developed: } \\
1 / 5\end{array}$ & $x$ & $x$ & $x$ \\
\hline & & Beyea et al. (29); 16 ears & $\begin{array}{l}\text { Resolved: } \\
1 / 1\end{array}$ & $\begin{array}{l}\text { Resolved: } \\
\text { Pulsatile: 10/10 } \\
\text { Non-pulsatile: - }\end{array}$ & $x$ & $\begin{array}{l}\text { Improved: } \\
\text { 2/16 } \\
\text { Preserved: } \\
\text { 14/16 }\end{array}$ & $x$ & $x$ & $x$ & Transient increase: 16/16 & $x$ & $x$ \\
\hline & & $\begin{array}{l}\text { Agrawal and Parnes (12); } \\
3 \text { ears }\end{array}$ & $x$ & $x$ & Resolved: 1/1 & $x$ & $x$ & $\begin{array}{l}\text { Resolved: } \\
3 / 3\end{array}$ & $\begin{array}{l}\text { Resolved: } \\
1 / 1\end{array}$ & $\begin{array}{l}\text { Transient increase: } 3 / 3 \\
\text { Resolved: } 3 / 3\end{array}$ & $x$ & $x$ \\
\hline & $P+R$ & Fiorino et al. (25); 6 ears & $x$ & $x$ & $x$ & $x$ & $x$ & $\begin{array}{l}\text { Improved: } \\
6 / 6\end{array}$ & $\begin{array}{l}\text { Improved: } \\
6 / 6\end{array}$ & Improved: 6/6 & $x$ & $x$ \\
\hline & R & Amoodi et al. (17); 4 ears & $x$ & $x$ & $x$ & $x$ & $x$ & $x$ & $x$ & Transient increase: $4 / 4$ & $x$ & $x$ \\
\hline & & Lundy et al. (15); 37 ears & $x$ & $x$ & $x$ & $x$ & $x$ & $x$ & $x$ & $\begin{array}{l}\text { Questionnaire: } \\
\text { Much better: } 29 \\
\text { Some better: } 5 \\
\text { Same: } 2 \\
\text { Worse: } 1\end{array}$ & $x$ & $x$ \\
\hline
\end{tabular}




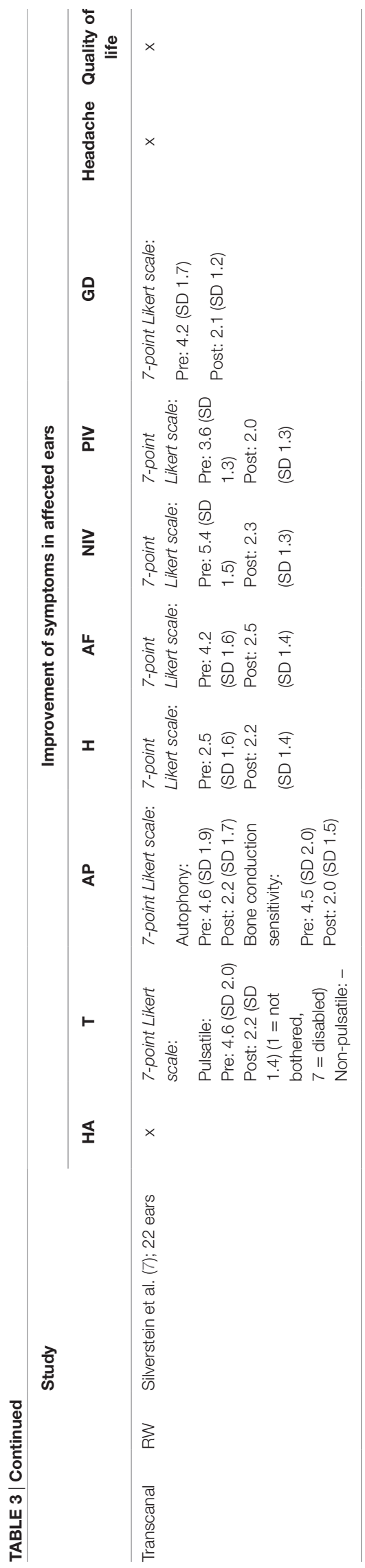

Conclusion: Existing evidence showed a non-significant improvement in subjective hearing following middle fossa plugging or plugging in combination with resurfacing and a preservation of hearing in the majority of patients following transmastoid plugging. Studies showed no subjective worsening after transcanal round window reinforcement. No evidence was available regarding the effect of other techniques. Grade of evidence: IV; grade of recommendation: $\mathrm{D}$.

\section{Aural Fullness}

Aural fullness was assessed in four studies. Plugging plus resurfacing via the middle fossa led to resolution of problems in 28 of the, in total, 33 affected patients and a new development of symptoms in $2 / 33$ patients $(19,20,30)$. No evidence was available on plugging or resurfacing via the middle fossa. Also no evidence was available regarding transmastoid plugging, resurfacing or a combination of both. Reinforcement of the round window resulted in a significant drop of score for aural fullness on the SCDS 7-point Likert scale $(n=22)(7)$.

Conclusion: Plugging plus resurfacing via the middle fossa and round window reinforcement led to a significant reduction in feeling of aural fullness. However, plugging via the middle fossa led to the new development of symptoms in two patients. No evidence was available for any of the other techniques. Grade of evidence: IV; grade of recommendation: D.

\section{Noise-Induced Vertigo}

Improvement of noise-induced vertigo was assessed in seven studies. No evidence was available on plugging via the middle fossa. Plugging plus resurfacing via the middle fossa resulted in a resolution of symptoms in $49 / 56$ patients (87.5\%) and a new development of symptoms in 1 of 56 patients $(14,19,20$, 30). Transmastoid plugging brought resolution in $7 / 8$ patients $(10,12)$ and transmastoid plugging plus resurfacing led to an improvement in $6 / 6$ patients (25). No evidence was available on transmastoid resurfacing. Round window reinforcement caused a significant reduction in SCDS score from 5.4 to 2.3 on the 7-point Likert scale $(n=22)(7)$.

Conclusion: Noise-induced vertigo improved in the majority of cases following plugging plus resurfacing via the middle fossa. No evidence was available regarding plugging or resurfacing via the middle fossa. Transmastoid plugging, a combination of plugging and resurfacing as well as round window reinforcement led to a significant reduction in noise-induced vertigo. No evidence was available on transmastoid resurfacing. Grade of evidence: IV; grade of recommendation: D.

\section{Pressure-Induced Vertigo}

Improvement of pressure-induced vertigo was assessed in 10 studies. No evidence was available regarding plugging via the middle fossa. Plugging plus resurfacing via the middle fossa resolved symptoms in 45/53 (85\%) patients and a new development of symptoms in 1 of 18 patients $(14,19,20,30)$. Resurfacing via the middle fossa brought resolution in $12 / 12$ patients (24). Transmastoid plugging led to resolution in $3 / 6$ patients $(10,12)$ and new development of symptoms in 1/5 (10). Plugging plus 
resurfacing via the same approach led to an improvement but not a resolution of symptoms in all patients (6/6) (25). No evidence was available on transmastoid resurfacing. Round window reinforcement caused a significant decrease in SCDS score for "dizziness with straining" from 2.8 to 1.8 and a significant decrease in score for "sensitivity to increased middle ear pressure" from 3.6 to 2.0 on the 7 -point Likert scale $(n=22)(7)$.

Conclusion: All assessed techniques led to improvement on pressure-induced vertigo in at least $50 \%$ of patients. Further comparison of the different techniques was not possible due to difference in outcome measures and a lack of evidence for some techniques. Grade of evidence: IV; grade of recommendation: D.

\section{Disequilibrium}

Disequilibrium was the most frequently assessed symptom throughout the studies. However, its severity was presented in several different outcome measures and was therefore difficult to compare. Plugging via the middle fossa resulted in a decrease of mean DHI from 48.7 (SD 23.4) to 38.2 (SD 30.7, $p=0.200$ ) (16). Plugging plus resurfacing via the middle fossa resulted in a resolution of symptoms in 38/51 patients and a new development of symptoms in 2 of 51 patients $(19,20,30)$. Furthermore, it led to an average decrease in DHI score of 20.45 and 26.0 $(p<0.01)$, respectively $(18,21)$. One study reported a transient increase in vertigo in the majority of patients $(4 / 5)$, but to an eventual improvement in all (5/5) patients (22). Resurfacing via the middle fossa showed resolution in 12/13 patients (24). Transmastoid plugging was reported to lead to improvements in $9 / 9$ patients $(12,25)$. However, one larger study reported that it caused transient disequilibrium in $16 / 16$ patients (29). Three studies reported on transmastoid resurfacing. In one study, 29/37 patients felt their disequilibrium had become "much better," 5/37 felt it was "some better," $2 / 37$ felt it had remained "the same" while $1 / 37$ reported "worsening" (15). In the other two studies, transmastoid resurfacing was followed by temporary disequilibrium in all cases $(4 / 4$ and $3 / 3)(12,17)$. Round window reinforcement caused the SCDS score to significantly drop from 4.2 to 2.1 for general disequilibrium on the 7-point Likert scale $(n=22)(7)$.

Conclusion: Disequilibrium improved or resolved in the majority of patients following all approaches that were assessed. Only transmastoid plugging plus resurfacing was not assessed. However, results were difficult to compare due to the variety of outcome measures. Grade of evidence: IV; grade of recommendation: D.

\section{Headache}

Improvement of headache was assessed in one study. Plugging plus resurfacing via the middle fossa led to a resolution of symptoms in $2 / 5$ patients $(p=1.0000)$ and to a new development of symptoms in 1 of 18 patients. No evidence was available on the other approaches.

Conclusion: Considering the small number of cases assessed it is not yet possible to draw a conclusion regarding the effect of surgery on symptoms of headache. Literature suggests that plugging plus resurfacing via the middle fossa can have a beneficial effect in some patients, but can also develop as result of surgery. Grade of evidence: IV; grade of recommendation: D.

\section{Quality of Life}

The quality of life is often represented by quality of adjusted life years, which can be calculated by different scores such as the HUV. The mean HUV of the general U.S. population is 0.80 (SD 0.29 ), while SCDS patients (including individuals not undergoing surgery) have a significantly lower mean score of 0.68 (SD 0.13, $p<0.01)$. The change in quality of life for patients undergoing surgery was addressed in 1 of the 19 studies. It reported an increase in HUV from 0.65 (SD 0.12) to 0.79 (SD 0.12, $p<0.001$ ) following middle fossa plugging (16). No evidence was available on the other approaches.

Conclusion: Literature suggests that plugging via the middle fossa can increase quality of life for patients with SCDS, who generally seem to have a significantly lower HUV in comparison to the general U.S. population. No comparison could be made between the different surgical techniques due to a lack of evidence. Grade of evidence: IV; grade of recommendation: D.

\section{Secondary Outcomes-Objective Improvement (Table 4) Audiometric Findings}

Pure-Tone Audiometry: $A C, B C, A B G$, and Sensorineural Hearing Loss (SNHL). Among all studies, 13 reported their audiometric outcomes. Due to the difference in outcome measures, it was, however, not feasible to pool the results (Table 2).

Following plugging plus resurfacing via the middle fossa, one study found an improvement of $\mathrm{AC}$ and a decrease in $\mathrm{BC}$, resulting in an at least partial $\mathrm{ABG}$ closure on all frequencies $(0.25-4 \mathrm{kHz})$ in the majority of cases within the study. SNHL was reported in a minority of cases (3/16) (19). Another study did not report thresholds, but described a general improvement of AC with an average of $10 \pm 23 \mathrm{~dB} H \mathrm{HL}(21)$. In contrast, a large-series study found no change over the lower frequencies and a significant decrease in $\mathrm{AC}$ and increase in $\mathrm{BC}$ for the higher frequencies $(2-8 \mathrm{kHz})$. It showed an acute high-frequency SNHL in $>50 \%$ of patients that persisted in $25 \%$ of them (13).

Another study reported a decrease in hearing in the majority of patients $(11 / 18)$, despite a reduction in mean of the largest ABGs. This effect is most likely due to an overall decrease in BC and not an increase in AC (18). The study further reported no change in hearing in $4 / 18$ patients, and improvement in the minority of patients $(3 / 18)(18)$.

One large-series study found no significant change in AC, BC, and $A B G$ over the frequencies $0.5-3 \mathrm{kHz}$. It did not address higher frequencies (20). Another study reported no significant AC or BC changes after surgery in the general SCDS population. The study also found a partial ABG closure of the ABG in a minority of patients $(2 / 29)$. However, in some cases SNHL did occur. It was associated with a positive previous history for stapes surgeries (23). One other smaller study did not report AC and BC values, but described a correction of pseudo-conductive hearing loss in the majority of patients (4/5) with only temporary SNHL loss in $3 / 5$ patients (22).

Resurfacing the dehiscence via the middle fossa was described in one study, which did not report $\mathrm{AC}$ and $\mathrm{BC}$ values, but described $A B G$ closure in all affected patients with a preoperative $\mathrm{ABG}>10 \mathrm{~dB}(2 / 2)$ and SNHL in only 1 out of 16 cases (24). 
TABLE 4 | Objective improvement of auditory and vestibular function.

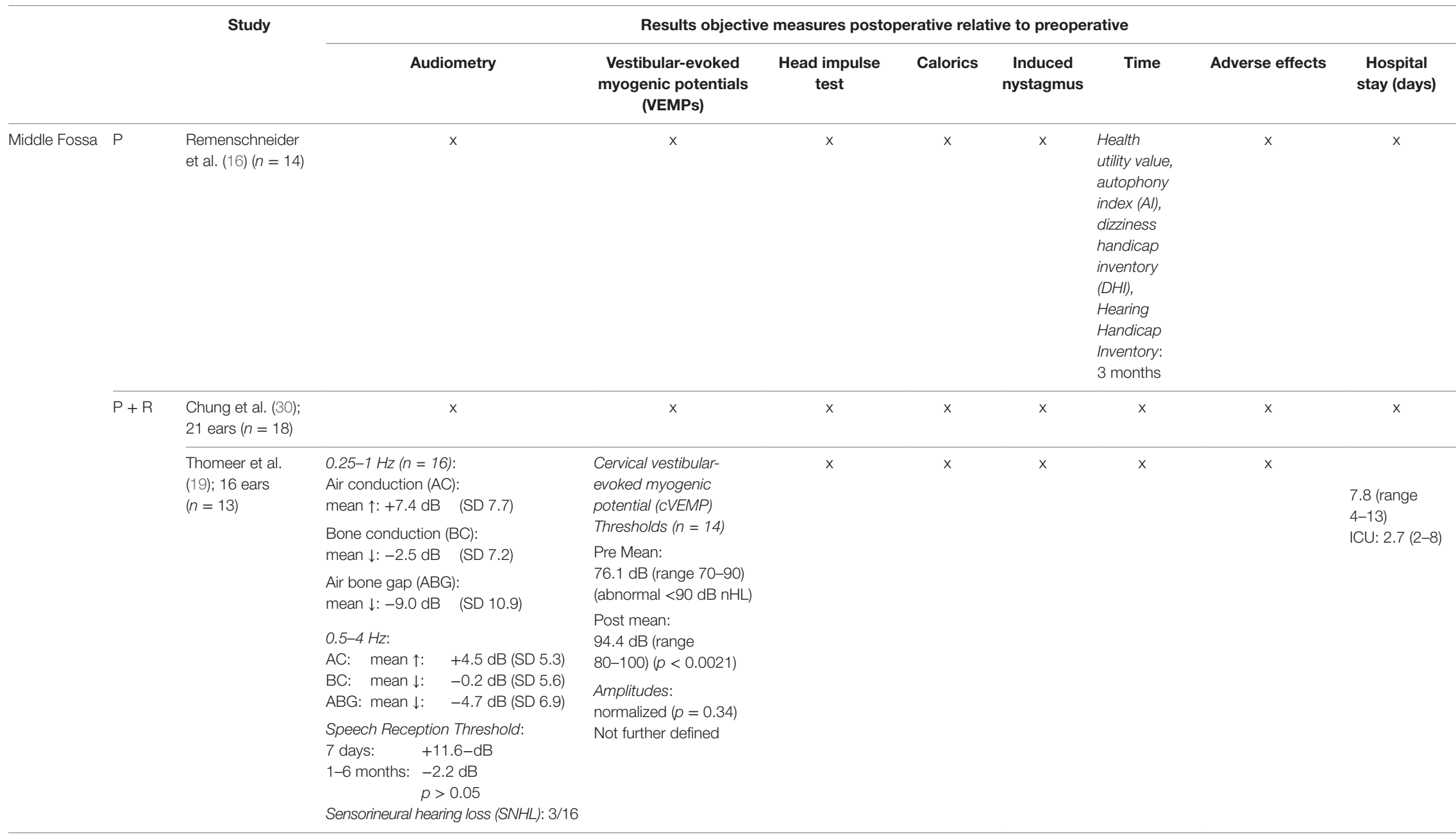


TABLE 4 | Continued

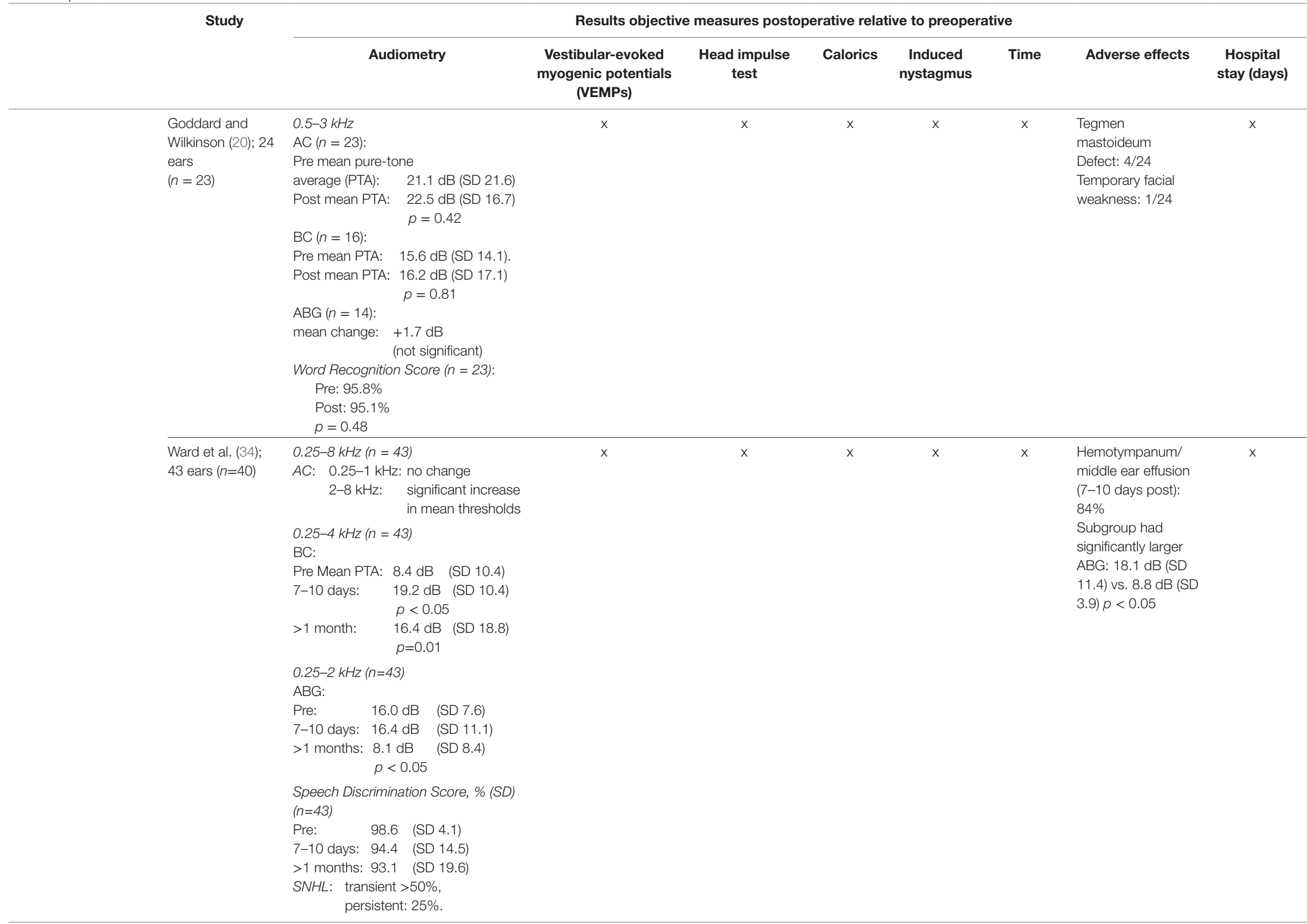




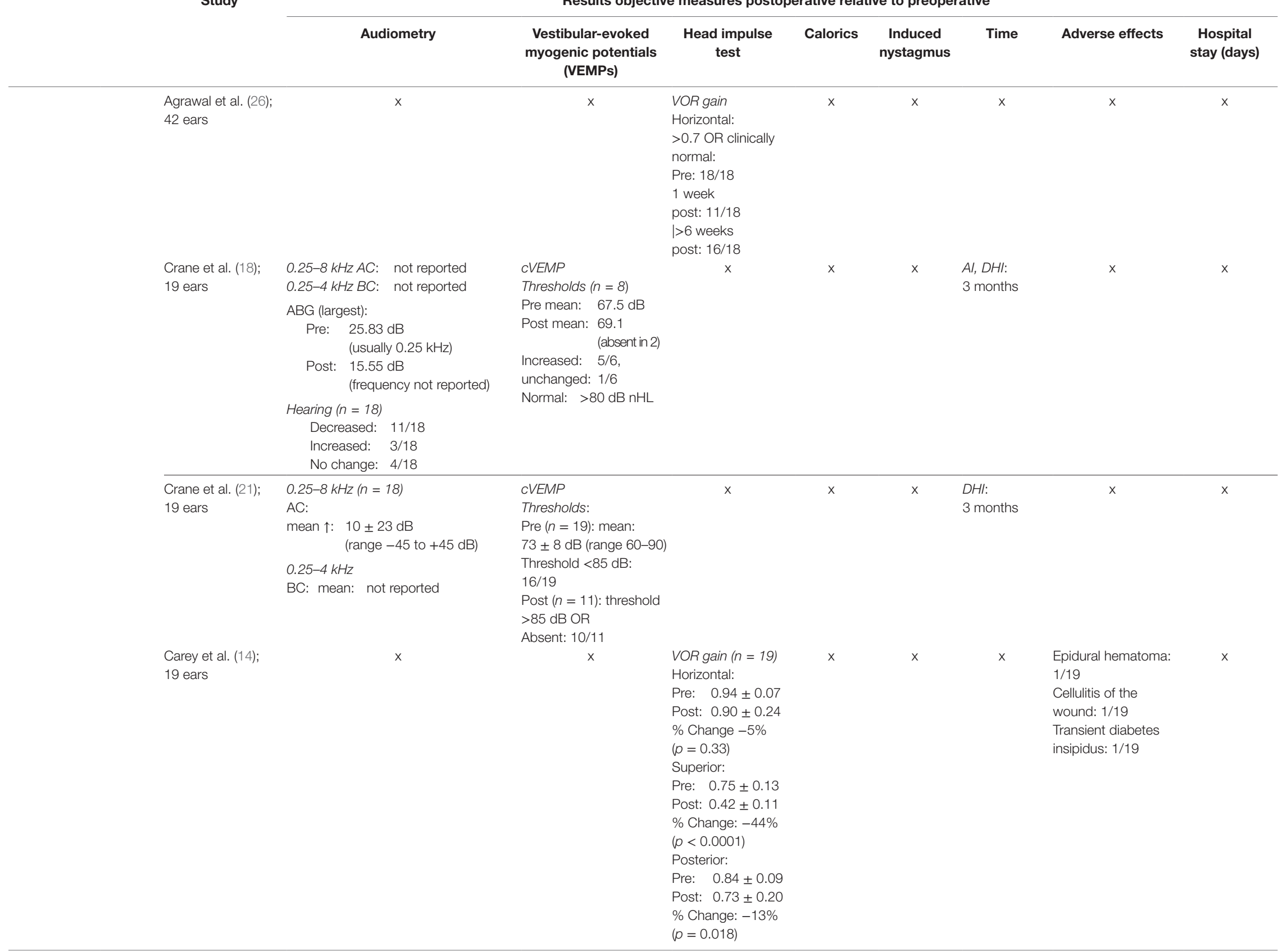


TABLE 4 | Continued

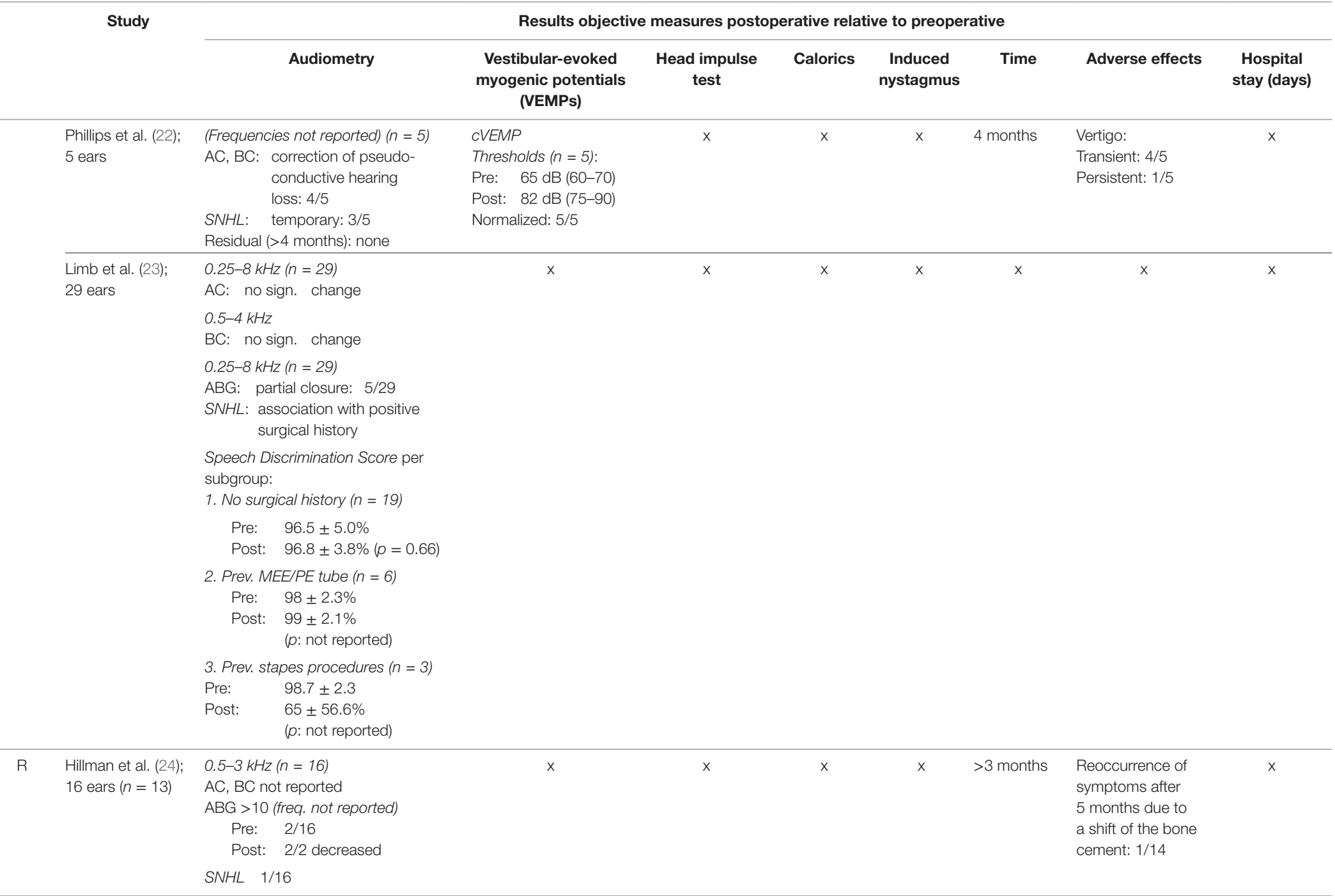




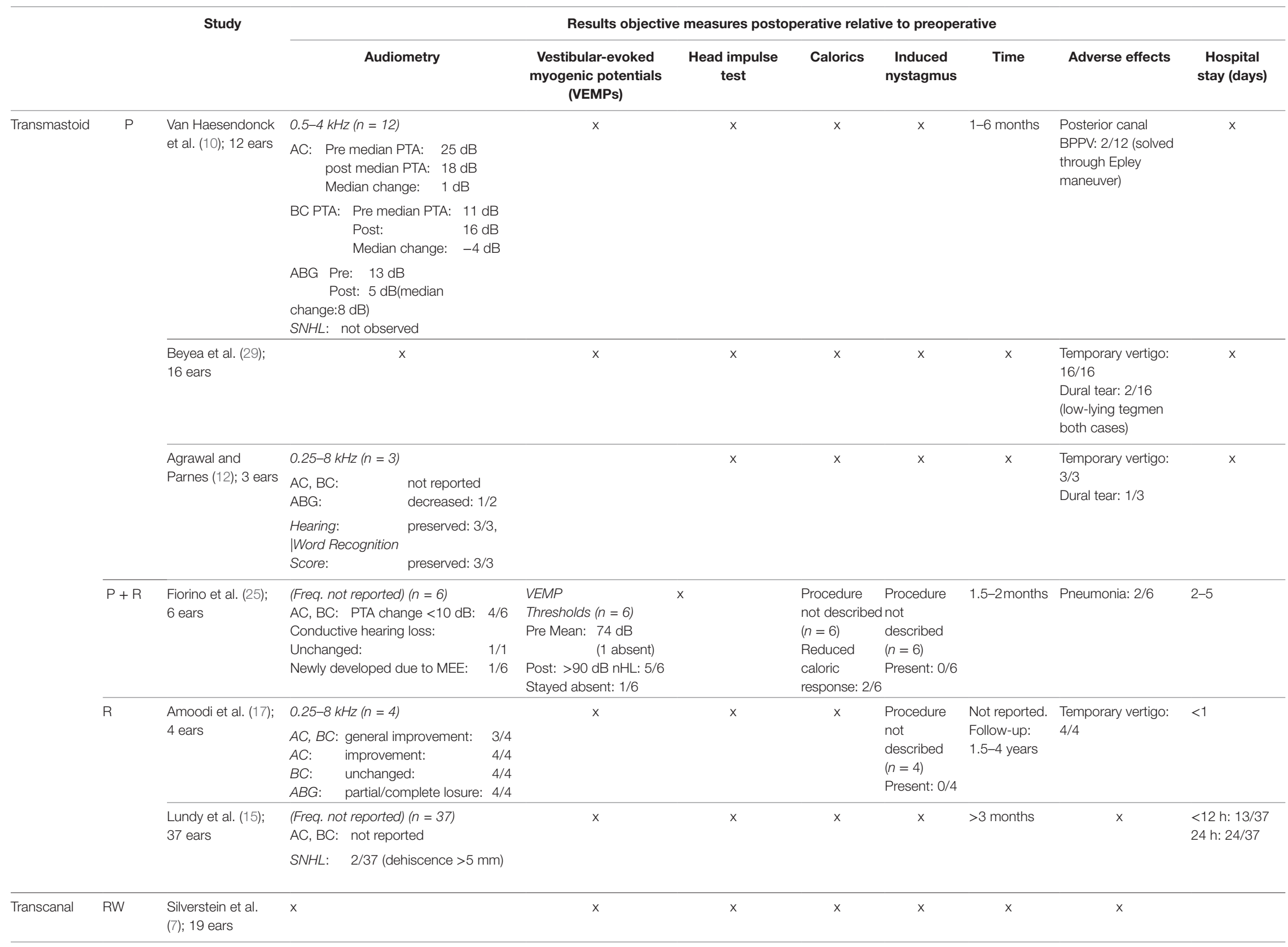


Following transmastoid plugging one study found decrease in median AC PTA from 25 to $18 \mathrm{~dB}$ and an increase in median BC PTA from 11 to $16 \mathrm{~dB}$. The ABG shrunk from 13 to $5 \mathrm{~dB}$ and no SNHL was observed (10). Two studies did not report audiometric data, but reported general results. One showed that transmastoid plugging resulted mainly in "preservation" (14/16) of hearing and in an "improvement" in 2/16 patients (29), and one study reported a decrease in $A B G$ in $1 / 2$ patients, "preservation" in hearing in $3 / 3$ patients (12).

Plugging plus resurfacing led to a change of PTA $<10 \mathrm{~dB}$ in $4 / 6$ patients, meaning there was no significant change in these patients. It was not described whether PTAs increased or decreased (25). Conductive hearing loss remained unchanged in one affected patient (1/1) and newly developed due to middle ear effusion in $1 / 6$ patients (25).

Transmastoid resurfacing led to an AC improvement (4/4) and no BC (4/4) in one study. The study reported at least partial closure of the ABG in all patients (4/4) (17). Another study did not announce audiometric data, but reported that SNHL was found in $2 / 37$ patients (15). Of these two patients, one was congenitally deaf. She had a small amount of residual hearing in the involved ear, which she lost postoperatively. The second patient had a drop in sensorineural levels from normal to 40 to $75 \mathrm{~dB}$ bone threshold. Both had a relatively large dehiscence of $5 \mathrm{~mm}$.

Conclusion: The way of assessing the results on $\mathrm{AC}, \mathrm{BC}$ and ABG varied significantly among the studies. No conclusion could be drawn regarding the effect of plugging plus resurfacing via the middle fossa on hearing outcomes. However, some existing literature suggests that it might cause high-frequency SNHL (13). Resurfacing via the middle fossa led to closure of the ABG in all affected cases and caused SNHL in only 1 of 16 cases (24). Transmastoid plugging, resurfacing and the combination of both seem to be a generally safe technique regarding hearing outcomes. Transmastoid resurfacing led to SNHL in very few cases $(2 / 41)$ $(15,17)$. However, in most patients the range of frequencies is not reported, which means that a high-frequency loss cannot entirely be ruled out. No assessment was done following round window reinforcement. Grade of evidence: IV; grade of recommendation: D.

Speech Audiometry. Speech audiometry was performed in very few studies and also assessed using different outcome measures, which did not allow pooling of the results. Outcome measures included: the SRT (19), the Word Recognition Score (20), and the Speech Discrimination Score $(13,23)$.

The SRT increased in the first week after surgery and decreased again under the baseline after 1-6 months (19), which demonstrated an only temporary hearing loss following plugging plus resurfacing via the middle fossa. The WRS remained unchanged following plugging plus resurfacing via the middle fossa $(23 / 23$ patients) (20) and transmastoid plugging ( $3 / 3$ patients) (12). The Speech Discrimination Score decreased significantly following plugging plus resurfacing via the middle fossa in the first 7-10 days and decreased further $>1$ month postoperatively $(n=43)$ (13).

Conclusion: Speech audiometry is performed in very few studies and the outcome measures vary. However, the assessment of speech audiometry is often part of the publication criteria when reporting hearing outcomes (31). It is therefore desirable that future reports on hearing outcome contain a standardized assessment of speech audiometry. Grade of evidence: IV; grade of recommendation: $\mathrm{D}$.

\section{Vestibular Findings}

Cervical and Ocular Vestibular-Evoked Myogenic Potential (cVEMP/oVEMP). Vestibular-evoked myogenic potentials were assessed in five studies of which four assessed cVEMPs and one did not announce if it concerned cVEMPs or oVEMPs (25). Thresholds were reported in the majority of studies, while amplitudes were only described in one study. Regarding the thresholds, the reference values varied per laboratory between "normal $>80$ " (18) "normal > $85 \mathrm{~dB}$ " (21), and "normal >90 dB" $(19,25)$.

Three studies assessed results after plugging plus resurfacing via the middle fossa. All three studies described an increase in mean VEMP threshold in the majority of patients $(18,19,21)$. However, in one study, the mean threshold remained $<70 \mathrm{~dB}(18)$, in one it increased to $>80 \mathrm{~dB}(21)$, and in one study it increased $>90 \mathrm{~dB}$ in all affected patients (19). In the latter study, amplitudes "normalized" after plugging plus resurfacing; however, reference values were not further defined (19). Another study reported that VEMP thresholds normalized in all cases (5/5), with the mean postoperative thresholds being $82 \mathrm{~dB}$. Reference values were not defined (22).

Regarding the transmastoid approach, VEMPs were studied only in one study where plugging plus resurfacing was performed (25). A normalization of VEMP thresholds $>90 \mathrm{~dB}$ in 5/6 cases was reported. In one case, the threshold remained absent (25).

Conclusion: Generally when the change in VEMP threshold was analyzed, an increase of the threshold was reported. However, one study did not report the exact type of VEMP that was assessed and number of studies did not report VEMP thresholds at all.

Plugging plus resurfacing the canal via the middle fossa seems to lead to an increase of VEMP thresholds in the majority of cases. No literature was available on the effects of resurfacing via the middle fossa and transmastoid plugging or resurfacing.

Little literature was available on the effect of transmastoid plugging plus resurfacing, but the existing studies showed that it leads to an increase in VEMP threshold $>90 \mathrm{~dB}$ in most cases.

No assessment was done following round window reinforcement. Furthermore, it is important to recognize that reference values for VEMP thresholds differ vastly between laboratories. Therefore, consensus is needed how to report on VEMPs. Grade of evidence: IV; grade of recommendation: D.

HIT and $v H I T(H I T / v H I T)$. Only two studies assessed the effect of surgery on the HIT. One other study mentioned HIT results for only two patients. No further pre- and postoperative data of the remaining population were reported (25). In both cases, the assessment followed plugging plus resurfacing via the middle fossa. One study assessed the horizontal canal VOR gain quantitatively (using vHIT) in the preoperative phase, qualitatively (using HIT) in the initial postoperative period (after 1 week) and qualitatively and quantitatively at more than 6 weeks postoperatively (26). It was found that the number of patients with a VOR gain $\geq 0.70$ dropped from $18 / 18$ preoperatively to $11 / 18$ one week after surgery, but then increased again to $16 / 18$ six weeks 
postoperatively (26) implying a transient loss of horizontal canal function.

The other study assessed the VOR gain for all canals using vHIT. A significant decrease in gain of $44 \%(p<0.0001)$ was found for the superior canal. The gain for the ipsilateral posterior canal dropped by $13 \%(p=0.018)$, while the average gain for the ipsilateral horizontal canal did not change significantly $(p=0.33)$ (14). No assessment was performed following the other approaches.

Conclusion: The evidence was not sufficient to compare the effect of the different surgical techniques on VOR gain. However, literature suggests that plugging plus resurfacing the dehiscence via the middle fossa leads to a significant decrease in VOR gain and therefore to a hypofunction of the superior canal. Furthermore, it can lead to temporary loss of function of the horizontal canal. Grade of evidence: IV; grade of recommendation: D.

Caloric Response. No literature was available on the change in caloric response following plugging, plugging plus resurfacing or resurfacing via the middle fossa. Caloric response was assessed in only one study (25), which analyzed the response following transmastoid plugging plus resurfacing. The study reported a reduced caloric response in 2/6 patients. Both cases had expressed a reduced response preoperatively. No literature was available analyzing caloric response following transmastoid resurfacing or plugging alone. No assessment was done following round window reinforcement.

Conclusion: The evidence for the effect of surgery on caloric response was not sufficient enough to draw conclusions, but existing literature suggests that there is no decrease in caloric response following transmastoid plugging plus resurfacing. Grade of evidence: IV; grade of recommendation: D.

Induced Nystagmus. No literature was available on the presence of induced nystagmus following plugging, plugging plus resurfacing or resurfacing via the middle fossa. It was assessed in only one study that analyzed the presence of nystagmus following transmastoid plugging plus resurfacing. Preoperatively sound-, pressure-, and Valsalva-induced nystagmus was seen in 5/6, $4 / 6$, and $5 / 6$ patients, respectively. No induced nystagmus was observed postoperatively (25). No literature was available that analyzed induced nystagmus following transmastoid resurfacing or plugging. Also, no assessment was done following round window reinforcement.

Conclusion: The evidence for the effect of surgery on the presence of induced nystagmus was not sufficient enough to compare the different surgical techniques, since only transmastoid plugging plus resurfacing was investigated. Grade of evidence: IV; grade of recommendation: $\mathrm{D}$.

\section{Adverse Effects}

The presence of adverse effects was assessed in 11 studies. No evidence was available on the effects of plugging via the middle fossa. Studies that looked at adverse effects after plugging plus resurfacing via the middle fossa reported the following: facial weakness (1/24), dural tears (4/24) (20), hemotympanum and middle ear effusions associated with a temporarily increased
ABG postoperatively (37/43) (13), epidural hematoma (1/19) (14), cellulitis of the wound (1/19) (14), and temporary diabetes insipidus (1/19) (14).

Resurfacing via the middle fossa led to a recurrence of symptoms after five months due to a shift of bone cement in one case (1/14) (24).

Transmastoid plugging caused posterior canal BPPV in 2/12 patients (10). Furthermore, a larger study reported dural tears in $2 / 16$ patients. Both patients had evidence of a low-lying tegmen (29).

Following plugging plus resurfacing, 2/6 patients developed pneumonia (25).

Transmastoid resurfacing was complicated by a dural tear in $1 / 3$ cases (12). No evidence regarding adverse effects following round window reinforcement via the ear canal was available.

Conclusion: The severity of local adverse effects was higher following the middle fossa approach than the transmastoid approach. A transient increase in vertigo seemed to develop in the majority of cases regardless of the approach. The risk for intraoperative dural tears using the transmastoid approach seemed to be higher in patients who had evidence of a low-lying tegmen. Grade of evidence: IV; grade of recommendation: D.

\section{Length of Hospital Stay}

The length of hospital stay was reported in four studies. No evidence was available on the effects of plugging via the middle fossa. Following plugging plus resurfacing via the middle fossa the average hospital stay was 7.8 days (range $4-13$ ), while the ICU stay was 2.7 days (range 2-8) (19). The exact reason why patients were admitted to the ICU was not reported. No evidence was available following resurfacing alone via the middle fossa. Also no evidence was available following transmastoid resurfacing.

Transmastoid plugging plus resurfacing was followed by an average hospital stay of 2-5 days (25). Transmastoid resurfacing showed the shortest hospital stays. One study reported an average hospital stay of $<24 \mathrm{~h}$ (17), and another study reported that $13 / 37$ patients were released on the day of surgery and 24/37 had one overnight stay but were also released within $24 \mathrm{~h}$ (15).

Conclusion: According to the available evidence, plugging plus resurfacing via the middle fossa resulted in a longer hospital stay than transmastoid plugging plus resurfacing or transmastoid resurfacing alone. Furthermore, ICU admission was reported in some cases following plugging plus resurfacing via the middle fossa, although it is unclear if this was performed routinely or triggered by a specific indication. Transmastoid resurfacing presented with the shortest hospital stays. This information has to be interpreted with great care since significant differences in health care organization may also explain hospital stay. Grade of evidence: IV; grade of recommendation: D.

\section{DISCUSSION}

This literature review highlights difficulties that researchers face when investigating a relatively new condition. The majority of included studies were retrospective and since SCDS is rare, studies inevitably have small sample sizes. Furthermore, the lack of standardized outcome measures made it difficult to pool or 
compare outcomes (Table 2). Comparison was difficult due to the following factors: anamnesis was mostly performed in a nonstandardized manner, which led to several different subjective (primary) outcome measures. Furthermore, several objective (secondary) outcome measures like audiometry, VEMPs, HIT, calorics, and presence of induced nystagmus were assessed in different ways. Therefore, most results from the different studies, regarding primary as well as secondary outcome measures, could only be summarized qualitatively and could not be statistically pooled.

Even though a number of significant reviews have been published since the last database search of this review, the majority of them did not address this particular issue $(32,33)$.

Some findings, however, were consistently reported. Overall an improvement of clinical symptoms and objective measures was found in the majority of patients regardless of the approach or closure technique. In most cases adverse effects or worsening of vertigo or hearing were temporary, typically resolving after several weeks. The surgical approach appears to determine the length of hospital stay, although differences in health care organization need to be considered. On average the middle fossa approach was followed by a longer hospital stay than the transmastoid and transcanal approaches. Adverse effects varied depending on the type of approach and anatomical features of the patient.

From the literature reviewed, it appears that surgery has a positive impact on the symptoms of SCDS but due to the use of different non-standardized outcome measures, surgical techniques could not reliably be compared. This is consistent with recent findings (34). Agreed upon standardized assessment tools, outcome measures and set timeframes are needed.

It is important to mention that not all the available diagnostic tools were addressed within this literature review, as some of them were not applied in any of the eligible studies. For example, it has previously been reported that the air conducted ocular VEMPs are superior to CVEMPs in the diagnosis of SCDS, and that electrocochleography could reflect the presence of a third mobile window (35-37). Future SCDS studies could therefore take these other diagnostic tools into consideration.

For a standardized protocol we strongly recommend the inclusion of assessments of symptom severity and changes in vestibular as well as auditory function in patients with SCDS before and after surgery at set times.

\section{Limitations \\ Review Level}

Although this review aimed to evaluate the available literature in a systematic fashion, the literature search was done by the first

\section{REFERENCES}

1. Guyatt GH, Oxman AD, Kunz R, Falck-Ytter Y, Vist GE, Liberati A, et al. Going from evidence to recommendations. $\mathrm{Br}$ Med J (2008) 336(7652):1049-51. doi:10.1136/bmj.39493.646875.AE

2. Agrawal Y, Ward BK, Minor LB. Vestibular dysfunction: prevalence, impact and need for targeted treatment. J Vestib Res (2013) 23(3):113-7. doi:10.3233/ ves-130498 author alone. The evaluation was done by the first and last author. Furthermore, not all available databases have been searched and the reviewing process was restricted only to published reports. No correspondence was established with the authors of the individual studies to obtain unpublished data. Therefore, publication bias might have influenced the conclusion of this review.

\section{Study Level}

On the study level, this review is limited by the retrospective nature of the majority of the analyzed studies. All reviewed studies show relatively weak internal validity due to small populations, high risk for both selection and information bias. The prospective study presented in this review consisted of a larger population, but was neither blinded nor randomized. Therefore, internal validity of this study was also moderate. The differences in methodology among studies made a comparison and pooling of the results impractical.

\section{Conclusion}

Generally, surgery has a positive impact on the symptoms of SCDS but due to the use of different outcome measures among studies, surgical techniques could not be compared quantitatively. Standardized assessment tools, outcome measures and set timeframes for patient follow-up are needed. Based on this review, we recommend the inclusion of assessments of symptom severity and changes in both vestibular as well as auditory function in patients with SCDS before and after surgery into the standardized protocol.

\section{AUTHOR CONTRIBUTIONS}

MO: study design, literature search, data analysis, and writing of the article. RS: study design and reviewing manuscript. HK, JT, VR, and YT: reviewing manuscript. RB: study design, data analysis, and reviewing manuscript.

\section{ACKNOWLEDGMENTS}

The authors would like to thank Bryan Ward and John Carey from the Department of Otolaryngology-Head and Neck Surgery of Johns Hopkins School of Medicine for reviewing a pre-publication version of this manuscript and suggesting edits that made it more precise and comprehensible.

\section{FUNDING}

The authors declare to have not received any funding from any third party concerning this review.

3. Minor LB. Superior canal dehiscence syndrome. Am J Otol (2000) 21(1):9-19. doi:10.1016/S0196-0709(00)80068-X

4. Minor LB. Clinical manifestations of superior semicircular canal dehiscence. Laryngoscope (2005) 115(10):1717-27. doi:10.1097/01.mlg.0000178324.55729.b7

5. Niesten M. Evaluation and Management of Superior Canal Dehiscence Syndrome. Utrecht: University of Utrecht (2014).

6. Lempert T, Olesen J, Furman J, Waterston J, Seemungal B, Carey J, et al. [Vestibular migraine: diagnostic criteria: consensus document of the 
Barany Society and the International Headache Society]. Nervenarzt (2013) 84(4):511-6. doi:10.1007/s00115-013-3768-x

7. Silverstein H, Kartush JM, Parnes LS, Poe DS, Babu SC, Levenson MJ, et al. Round window reinforcement for superior semicircular canal dehiscence: a retrospective multi-center case series. Am J Otolaryngol (2014) 35(3):286-93. doi:10.1016/j.amjoto.2014.02.016

8. Ziylan F, Kinaci A, Beynon AJ, Kunst HP. A comparison of surgical treatments for superior semicircular canal dehiscence: a systematic review. Otol Neurotol (2017) 38(1):1-10. doi:10.1097/MAO.0000000000001277

9. Gioacchini FM, Alicandri-Ciufelli M, Kaleci S, Scarpa A, Cassandro E, Re M. Outcomes and complications in superior semicircular canal dehiscence surgery: a systematic review. Laryngoscope (2016) 126(5):1218-24. doi:10.1002/ lary. 25662

10. Van Haesendonck G, Van de Heyning P, Van Rompaey V. Retrospective cohort study on hearing outcome after transmastoid plugging in superior semicircular canal dehiscence syndrome: our experience. Clin Otolaryngol (2016) 41(5):601-6. doi:10.1111/coa.12539

11. Moher D, Liberati A, Tetzlaff J, Altman DG, Group P. Preferred reporting items for systematic reviews and meta-analyses: the PRISMA statement. Int J Surg (2010) 8(5):336-41. doi:10.1016/j.ijsu.2010.02.007

12. Agrawal SK, Parnes LS. Transmastoid superior semicircular canal occlusion. Otol Neurotol (2008) 29(3):363-7. doi:10.1097/mao.0b013e3181616c9d

13. Ward BK, Agrawal Y, Nguyen E, Della Santina CC, Limb CJ, Francis HW, et al. Hearing outcomes after surgical plugging of the superior semicircular canal by a middle cranial fossa approach. Otol Neurotol (2012) 33(8):1386-91. doi:10.1097/MAO.0b013e318268d20d

14. Carey JP, Migliaccio AA, Minor LB. Semicircular canal function before and after surgery for superior canal dehiscence. Otol Neurotol (2007) 28(3):356-64. doi:10.1097/01.mao.0000253284.40995.d8

15. Lundy L, Zapala D, Moushey J. Cartilage cap occlusion technique for dehiscent superior semicircular canals. Otol Neurotol (2011) 32(8):1281-4. doi:10.1097/ MAO.0b013e31822e5b27

16. Remenschneider AK, Owoc M, Kozin ED, McKenna MJ, Lee DJ, Jung DH. Health utility improves after surgery for superior canal dehiscence syndrome. Otol Neurotol (2015) 36(10):1695-701. doi:10.1097/MAO.0000000000000886

17. Amoodi HA, Makki FM, McNeil M, Bance M. Transmastoid resurfacing of superior semicircular canal dehiscence. Laryngoscope (2011) 121(5):1117-23. doi:10.1002/lary.21398

18. Crane BT, Lin FR, Minor LB, Carey JP. Improvement in autophony symptoms after superior canal dehiscence repair. Otol Neurotol (2010) 31(1):140-6. doi:10.1097/MAO.0b013e3181bc39ab

19. Thomeer H, Bonnard D, Castetbon V, Franco-Vidal V, Darrouzet P, Darrouzet $\mathrm{V}$. Long-term results of middle fossa plugging of superior semicircular canal dehiscences: clinically and instrumentally demonstrated efficiency in a retrospective series of 16 ears. Eur Arch Otorhinolaryngol (2016) 273(7):1689-96. doi:10.1007/s00405-015-3715-5

20. Goddard JC, Wilkinson EP. Outcomes following semicircular canal plugging. Otolaryngol Head Neck Surg (2014) 151(3):478-83. doi:10.1177/0194599814538233

21. Crane BT, Minor LB, Carey JP. Superior canal dehiscence plugging reduces dizziness handicap. Laryngoscope (2008) 118(10):1809-13. doi:10.1097/ MLG.0b013e31817f18fa

22. Phillips DJ, Souter MA, Vitkovic J, Briggs RJ. Diagnosis and outcomes of middle cranial fossa repair for patients with superior semicircular canal dehiscence syndrome. J Clin Neurosci (2010) 17(3):339-41. doi:10.1016/j. jocn.2009.06.021
23. Limb CJ, Carey JP, Srireddy S, Minor LB. Auditory function in patients with surgically treated superior semicircular canal dehiscence. Otol Neurotol (2006) 27(7):969-80. doi:10.1097/01.mao.0000235376.70492.8e

24. Hillman TA, Kertesz TR, Hadley K, Shelton C. Reversible peripheral vestibulopathy: the treatment of superior canal dehiscence. Otolaryngol Head Neck Surg (2006) 134(3):431-6. doi:10.1016/j.otohns.2005.10.033

25. Fiorino F, Barbieri F, Pizzini FB, Beltramello A. A dehiscent superior semicircular canal may be plugged and resurfaced via the transmastoid route. Otol Neurotol (2010) 31(1):136-9. doi:10.1097/MAO.0b013e3181b76b9e

26. Agrawal Y, Migliaccio AA, Minor LB, Carey JP. Vestibular hypofunction in the initial postoperative period after surgical treatment of superior semicircular canal dehiscence. Otol Neurotol (2009) 30(4):502-6. doi:10.1097/ MAO.0b013e3181a32d69

27. Surgery AAoO-HaN. (2017). Available from: http://www.entnet.org/content/ clinical-practice-guidelines

28. Shekelle PG, Woolf SH, Eccles M, Grimshaw J. Developing clinical guidelines. West J Med (1999) 170(6):348.

29. Beyea JA, Agrawal SK, Parnes LS. Transmastoid semicircular canal occlusion: a safe and highly effective treatment for benign paroxysmal positional vertigo and superior canal dehiscence. Laryngoscope (2012) 122(8):1862-6. doi:10.1002/lary.23390

30. Chung LK, Ung N, Spasic M, Nagasawa DT, Pelargos PE, Thill K, et al. Clinical outcomes of middle fossa craniotomy for superior semicircular canal dehiscence repair.J Neurosurg (2016) 125(5):1187-93.doi:10.3171/2015.8.JNS15391

31. Gurgel RK, Jackler RK, Dobie RA, Popelka GR. A new standardized format for reporting hearing outcome in clinical trials. Otolaryngol Head Neck Surg (2012) 147(5):803-7. doi:10.1177/0194599812458401

32. Diaz MP, Lesser JCC, Alarcón AV. Superior semicircular canal dehiscence syndrome-diagnosis and surgical management. Int Arch Otorhinolaryngol (2017) 21(02):195-8. doi:10.1055/s-0037-1599785

33. Bi WL, Brewster R, Poe D, Vernick D, Lee DJ, Eduardo Corrales C, et al. Superior semicircular canal dehiscence syndrome. J Neurosurg (2017):1-9. doi:10.3171/2016.9.JNS16503

34. Ward BK, Carey JP, Minor LB. Superior canal dehiscence syndrome: lessons from the first 20 years. Front Neurol (2017) 8:177. doi:10.3389/fneur.2017.00177

35. Zuniga MG, Janky KL, Nguyen KD, Welgampola MS, Carey JP. Ocular vs. cervical VEMPs in the diagnosis of superior semicircular canal dehiscence syndrome. Otol Neurotol (2013) 34(1):121. doi:10.1097/MAO.0b013e31827136b0

36. Adams ME, Kileny PR, Telian SA, El-Kashlan HK, Heidenreich KD, Mannarelli GR, et al. Electrocochleography as a diagnostic and intraoperative adjunct in superior semicircular canal dehiscence syndrome. Otol Neurotol (2011) 32(9):1506-12. doi:10.1097/MAO.0b013e3182382a7c

37. Arts HA, Adams ME, Telian SA, El-Kashlan H, Kileny PR. Reversible electrocochleographic abnormalities in superior canal dehiscence. Otol Neurotol (2009) 30(1):79-86. doi:10.1097/MAO.0b013e31818d1b51

Conflict of Interest Statement: The authors declare that the research was conducted in the absence of any commercial or financial relationships that could be construed as a potential conflict of interest.

Copyright () 2017 Ossen, Stokroos, Kingma, van Tongeren, Van Rompaey, Temel and van de Berg. This is an open-access article distributed under the terms of the Creative Commons Attribution License (CC BY). The use, distribution or reproduction in other forums is permitted, provided the original author(s) or licensor are credited and that the original publication in this journal is cited, in accordance with accepted academic practice. No use, distribution or reproduction is permitted which does not comply with these terms. 